\title{
A two-layer non-hydrostatic landslide model for tsunami generation on irregular bathymetry
}

\author{
Cheng Zhang, University of Delaware,chzhang@udel.edu \\ James T. Kirby, University of Delaware,kirby@udel.edu \\ Stéphan T. Grilli, University of Rhode Island,grilli@uri.edu \\ Fengyan Shi, University of Delaware,fyshi@udel.edu \\ Gangfeng Ma, Old Dominion University,gma@odu.edu
}

In this study, a two-layer landslide model is presented for investigating submarine landslides and generated waves that propagate over irregular bathymetry. The landslide is described as either a mudflow or a fully saturated granular flow, which are distinguished by using different rheological closure based on physical principles. Depthaveraged governing equations for the landslide are derived in a regular Cartesian coordinate system, and take into account the effect of vertical acceleration and interface traction from the upper-layer water. In addition, sediment erosion from basal boundary and water entrainment are also considered. Tsunami waves generated by the landslide are simulated by the threedimensional non-hydrostatic wave model NHWAVE (Ma et al., 2012). The governing equations for both the lowerlayer slide and the upper-layer water body are solved using a Godunov-type finite volume TVD scheme in space and a Strong Stability-Preserving (SSP) RungeKutta scheme in time.

In a regular Cartesian coordinate frame, non-dimensional analysis shows that vertical acceleration of the landslide is considerable when slope becomes steep, leading to a deviation from hydrostatic pressure in the slide volume. Therefore, a non-hydrostatic model is included to take the effect into account and correct the bottom pressure and velocity.

In this study, the slide volume is idealized as a homogeneous continuum, with several alternative choices of Newtonian or non-Newtonian rheologies available for characterizing the particular type of flow involved. In the landslide model, three rheological stress closures are included for mudflow and three for granular flow. The mudflow closures are laminar flow model, turbulent flow model and Bingham fluid model (Jiang \& Leblond, 1993 and Imran et al., 2001), while the granular flow closures include Coulomb friction model (Savage \& Hutter, 1989), Voellmy friction model (Coulomb friction+ turbulent flow, Hungr \& McDougall, 2009) and $\mu(\mathrm{I})$ rheology model (Gray \& Edwards, 2014).

The Bed erosion rate is estimated in a similar manner as described in Iverson \& Ouyang (2015), in which the formula is derived from a two-layer erosion theory. The theory considers the interaction between an upper layer of moving mass and a lower layer of static and erodible bed. To close the formula, a Coulomb friction model is used to estimate the stresses of the static bed.

To calculate the interface traction between the waterlayer and slide-layer, another two-layer entrainment theory is used. The slide-layer stresses at the interface can be expressed with known water-layer stresses and deformation of the interface. Meanwhile, the water entrainment rate of the slide layer is estimated by the change of the mass porosity, which is controlled by the soil dilatancy effect during the slide motion (Iverson \& George, 2014).
The model is tested against some analytical solutions and experimental results for both landslide motions and tsunami wave generation. For example, Figure 1 shows the modeled and measured waves at wave gauge locations for a laboratory experiment on a submarine slide of homogeneous glass beads, described in Grilli et al. (2017).

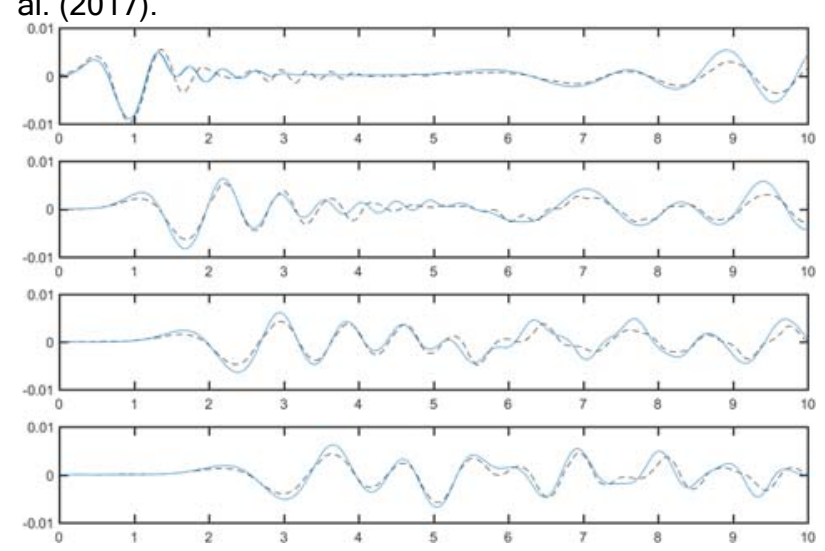

Figure 1 Comparison of simulated (solid lines) and measured (dashed lines) at four gauge locations in experiments of Grilli et al. (2017)

\section{REFERENCES}

Gray, J., and A. Edwards (2014), A depth-averaged $\mu(\mathrm{I})$-rheology for shallow granular free-surface flows, Journal of Fluid Mechanics, 755, 503-534.

Grilli, S. T., M. Shelby, O. Kimmoun, G. Dupont, D. Nicolsky, G. Ma, J. T. Kirby, and F. Shi (2017), Modeling coastal tsunami hazard from submarine mass failures: Effect of slide rheology, experimental validation, and case studies off the us east coast, Natural Hazards, 86(1), 353391.

Hungr, O., and McDougall, S. (2009). Two numerical models for landslide dynamic analysis. Computers and Geosciences, 35(5), 978-992.

Imran, J., G. Parker, J. Locat, and H. Lee (2001), 1D numerical model of muddy subaqueous and subaerial debris flows, Journal of Hydraulic Engineering, 127(11), 959-968.

Iverson, R. M., and D. L. George (2014), A depthaveraged debris-flow model that includes the effects of evolving dilatancy. I. Physical basis, Proceedings of the Royal Society of London A, 470(20130819), 1-31.

Iverson, R. M., and C. Ouyang (2015), Entrainment of bed material by earth-surface mass flows: Review and reformulation of depth-integrated theory, Reviews of Geophysics, 53(1), 27-58.

Jiang, L., and P. H. LeBlond (1993), Numerical modeling of an underwater bingham plastic mudslide and the waves which it generates, Journal of Geophysical Research: Oceans, 98(C6), 10,303-10,317.

Savage, S. B., and K. Hutter (1989), The motion of a finite mass of granular material down a rough incline, Journal of Fluid Mechanics, 199, 177-215. 